\title{
Geoecological investigations of artificial radionuclides in the aquatic system of the Ob River and Kara Sea
}

\author{
O. Stepanets ${ }^{1}$, A. Borisov ${ }^{1}$, A. Ligaev ${ }^{1}$, A. Travkina ${ }^{1}$ and J. Brown² \\ ${ }^{1}$ Vernadsky Institute of Geochemistry and Analytical Chemistry, Russian Academy \\ of Sciences, Moscow, Russia \\ ${ }^{2}$ Norwegian Radiation Protection Authority
}

\begin{abstract}
Numerous studies have considered whether run-off from large Siberian rivers, in particular the $\mathrm{Ob}$ River, has the potential to transport radioactive contaminants from the nuclear sites - SPA "Mayak" and Siberian Chemical Combine (SCC), located in the vicinity of these rivers, to distant locations including the Kara Sea.

The plutonium-producing radiochemical plant of SPA "Mayak" stored a lot of radioactive wastes in Lake Karachai. Radioelements are carried to the rivers with flood and ground waters [1]. As contamination is transported, radioactivity is removed through Techa-Iset'-Tobol-Ob river system but has the potential to reach the Kara Sea and further to other seas within the Arctic basin via ocean currents. The Siberian Chemical Combine, is located in Seversk city on the bank of Tom River, that drains into the Ob network. SCC liquid wastes were detected in the Tom River, which flows into the Ob River [2].

In this paper the data of our investigations during last years on studying the radioecological situation in two parts of the Ob river-Kara Sea aquatic system -Ob-Irtysh river's system and Ob Bay and adjacent part of the Kara Sea, with a main focus on the behavior and migration pathways of man-made radionuclides are presented.
\end{abstract}

\section{MATERIALS AND METHODS}

We studied two water areas. The first was in the central part of the the $\mathrm{Ob}$ river. The most important site in the catchment of the $\mathrm{Ob}$ river is the Ob-Irtysh water system. Within this region, the $\mathrm{Ob}$ and Irtysh are the main rivers, forming together with numerous inflows, lakes and bogs an extensive hydrographic network. Field investigations were carried out in the central part of the Ob river in 2006 during a period of low water and in 2007 during a period high water.

The second area includes the Ob Bay and the adjacent part of the Kara Sea. The researches were carried out in 2002-2004 on board r/v Akademik Boris Petrov (BP) and in 2007 on board r/v Akademik Mstislav Keldysh (MsK).

${ }^{137} \mathrm{Cs}$ and ${ }^{210} \mathrm{~Pb}$ in the sediments were determined by direct gamma spectrometry using HPGe detector, active diameter $70 \mathrm{~mm}$, active area $3800 \mathrm{~mm}^{3}$. The determination of ${ }^{137} \mathrm{Cs},{ }^{90} \mathrm{Sr}$ and ${ }^{239,240} \mathrm{Pu}$ in water and sediment samples was carried out by standard radiochemical methods [3].

\section{RESULTS AND CONCLUSIONS}

The map of sampling stations in area 1 is presented in figure 1.

The first research region consisted of three sampling areas. The first site was located upstream of the Ob confluence with the Irtysh River enabling an estimate of the SCC contribution to the total antropogenically derived contamination to be estimated. The second site was located at the Irtysh river upstream, in order to study the impact of the SPA "Mayak" discharges of radionuclides to the river. The third sampling site was situated downstream of the $\mathrm{Ob}$ and Irtysh confluence in order to characterize the 


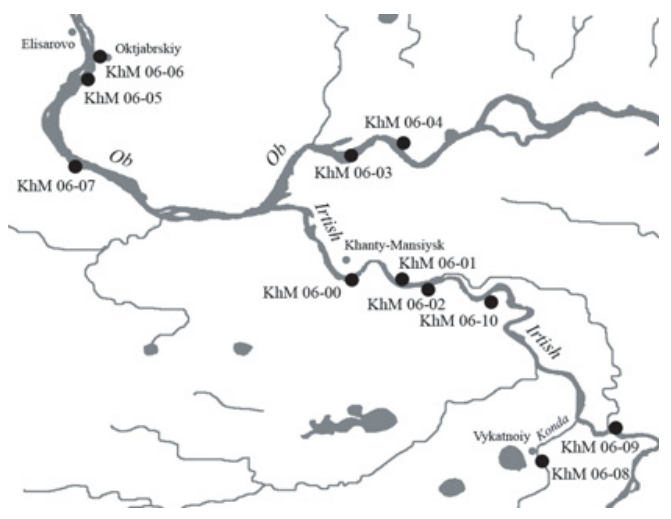

Figure 1. Sampling location.

combined effect of radioactive and chemical contamination of the middle section of the Ob River from the two separate sources.

Sediment and water samples were taken in small bays, formed by channels at low water along the coast of the main river channel.

Data on activity concentrations of ${ }^{137} \mathrm{Cs}$ in surface layers of sediment are presented in Table 1. ${ }^{137} \mathrm{Cs}$ activity concentration can be seen to be generally low. The maximum concentration of ${ }^{137} \mathrm{Cs}$ was measured at a site on the river $\mathrm{Ob}$ after the $\mathrm{Ob}$ and Irtysh rivers merge. Thereafter, relatively elevated ${ }^{137} \mathrm{Cs}$ concentrations were found in $\mathrm{Ob}$ River.

Table 1. Activity of ${ }^{137} \mathrm{Cs}$ in the surface sediments.

\begin{tabular}{|c|c|c|c|c|c|}
\hline Region & Station & Cs-137, Bq/kg & Region & Station & Cs-137, Bq/kg \\
\hline Ob before mixing with Irtysh & KhM06-03 & $2.1 \pm 0.2$ & Irtysh river & KhM06-01 & $1.1 \pm 0.2$ \\
\hline Ob before mixing with Irtysh & KhM06-04 & $1.0 \pm 0.4$ & Irtysh river & KhM06-02 & $0.3 \pm 0.1$ \\
\hline Ob after mixing with Irtysh & KhM06-05 & $1.9 \pm 0.3$ & Irtysh river & KhM06-02a & $0.3 \pm 0.1$ \\
\hline Ob after mixing with Irtysh & KhM06-06 & $0.8 \pm 0.3$ & Irtysh river & KhM06-08 & $0.5 \pm 0.2$ \\
\hline
\end{tabular}

The level of the ${ }^{239,240} \mathrm{Pu}$ radioactivity in surface layer of sediments by results of researches of 20062007 was low enough that has not allowed to make any conclusions about parameters of distribution given radionuclide on various sites Ob-Irtysh river system. Obtained results are presented in table 2.

Table 2. Activity of plutonium isotopes in surface sediments.

\begin{tabular}{|c|c|c|}
\hline No. of station & location & $\begin{array}{c}\text { Activity of Pu-239,240, } \\
\mathrm{Bq} / \mathrm{kg}\end{array}$ \\
\hline MsK-4954 & Kara Sea & $<0,01$ \\
\hline MsK-5000 & Kara Sea & 0,24 \\
\hline BP-3-14 & Kara Sea & 0,4 \\
\hline BP-32 & Kara Sea & 0,75 \\
\hline BP-26 & Kara Sea & 1,13 \\
\hline MsK-4995 & Ob's estuary & 0,29 \\
\hline MsK-4998 & Ob's estuary & 0,16 \\
\hline BP-40 & Ob's estuary & 5,85 \\
\hline BP01-72 & Ob's estuary & 0,22 \\
\hline BP01-70 & Ob's estuary & $<0,01$ \\
\hline XM06-08 & Ob river & $<0,01$ \\
\hline XM06-05 & Ob river & 0,018 \\
\hline
\end{tabular}


Data on radionuclide activity concentrations of ${ }^{137} \mathrm{Cs}$, plutonium isotops and ${ }^{90} \mathrm{Sr}$ in water samples are presented in table 3. The results show that suspended matter (nominally defined as $>0.45 \mu \mathrm{m}$ ) can retain more than $90 \%{ }^{137} \mathrm{Cs}$ whereas a smaller fraction $\left(\leq 31 \%\right.$ in all cases) of ${ }^{90} \mathrm{Sr}$ is associated with suspended material. This means that a large fraction of radionuclides is transported by river flow and enters in mixing zone in association with suspended matter. Radiocesium concentrations in water samples of mixing zone are higher than in the river area and may be explained by a relatively high content of clay materials in the surface sediments of the mixing zone.

Table 3. Levels of ${ }^{137} \mathrm{Cs},{ }^{90} \mathrm{Sr}$ and plutonium isotopes in particle and dissolved fraction of water samples in Ob-Irtysh system.

\begin{tabular}{|c|c|c|c|c|c|c|c|c|c|}
\hline $\begin{array}{c}\text { Station } \\
\text { no. }\end{array}$ & \multicolumn{3}{|c|}{ Cs-137 } & \multicolumn{3}{|c|}{ Sr-90 } & \multicolumn{3}{|c|}{ Pu-239.240 } \\
\cline { 2 - 11 } & $\begin{array}{c}\sum_{\text {total }} \\
\mathrm{Bq} / \mathrm{m}^{3}\end{array}$ & $\begin{array}{c}>0.45 \\
\mathrm{mkm} \\
\%\end{array}$ & $\begin{array}{c}<0.45 \\
\mathrm{mkm} \\
\%\end{array}$ & $\begin{array}{c}\sum_{\text {total }} \\
\mathrm{Bq} / \mathrm{m}^{3}\end{array}$ & $\begin{array}{c}>0.45 \\
\mathrm{mkm} \\
\%\end{array}$ & $\begin{array}{c}<0.45 \\
\mathrm{mkm} \\
\%\end{array}$ & $\begin{array}{c}\sum_{\text {total }^{3}} \\
\mathrm{~Bq} / \mathrm{m}^{3}\end{array}$ & $\begin{array}{c}>0.45 \\
\mathrm{mkm} \\
\%\end{array}$ & $\begin{array}{c}<0.45 \\
\mathrm{mkm} \\
\%\end{array}$ \\
\hline XM06-01 & 0.42 & 99 & 1 & 13.7 & 18 & 82 & - & - & - \\
\hline XM06-03 & 0.33 & 85 & 15 & 5.3 & 30 & 70 & - & - & - \\
\hline XM06-05 & 0.75 & 98 & 2 & 6.5 & 11 & 89 & - & - & - \\
\hline XM06-07 & 0.51 & 93 & 7 & - & - & - & - & - & - \\
\hline XM06-08 & 0.82 & 62 & 38 & 4.9 & 31 & 69 & - & - & - \\
\hline XM07-01 & 0.40 & 72 & 28 & 8.4 & 44 & 56 & 3.1 & - & - \\
\hline XM07-02 & 0.46 & 63 & 37 & 4.0 & - & - & - & - & - \\
\hline XM07-03 & 0.41 & 66 & 34 & 7.7 & - & - & 4.0 & - & - \\
\hline
\end{tabular}

It is necessary to note ultra-small contents of radionuclides in water-soluble fractions. So, total concentration Cs-137, Sr-90, Pu-239.240 in river water was within the limits of $0.3-0.8 \mathrm{~Bq} / \mathrm{m}^{3}$; 4.9-13.7 Bq/ $\mathrm{m}^{3} ; 0.1-4.0 \mathrm{~Bq} / \mathrm{m}^{3}$ accordingly. The highest values of specific concentration caesium-137 and strontium-90 are fixed on a site of the river Irtysh before merge of the rivers Obs and Irtysh.

On the basis of consideration of all data set it is possible to ascertain, that migration of radionuclides on the given site of river system can be carried out in several forms. For caesium-137, basically, in the form strongly fixed in structure of a suspension and to a lesser degree, it is especial during small water, in the soluble form. For strontium-90 migration in the soluble form, on the contrary, is more characteristic, it is possible in the form colloides. In this case it is possible to believe, that with a water stream up to estuares zones and an adjacent part of Kara Sea can reach radionuclides some caesium-137 in the form strongly fixed in structure of suspensions.

The results received by us on levels of specific concentration of radionuclides in water-soluble fraction and on a suspension confirm, that the basic carry radionuclides on a river stream in system the river the sea is carried out mainly with the suspended material of a river drain.

The levels of ${ }^{239,240} \mathrm{Pu}$ activity in water samples was $0.1-4.0 \mathrm{~Bq} / \mathrm{m}^{3}$. The data suggest an absence of inflow to the $\mathrm{Ob}$ Bay of additional plutonium isotopes from the river $\mathrm{Ob}$ in recent times spanning a few years. Despite the generally low activity concentrations of ${ }^{137} \mathrm{Cs}$ and ${ }^{90} \mathrm{Sr}$ in water, their highest values are found in the river Irtysh and river Konda, a tributary of the River Irtysh. This suggests a more significant influence of the river Irtysh (which characterize effect of radioactive contamination from the plutonium producing radiochemical plant of SPA "Mayak" through Techa-Iset'-Tobol-Irtysh river system) on the total radioactive contamination in Ob-Irtysh aquatic system.

After passing through the estuarial zone radionuclides with water streams get in a coastal part of Kara sea where their distribution in sediments depends on hydrophysical and geochemical parameters of the environment (figure 2).

Influence of impurities from the drains of Yenisei river on the radioecological situation of Kara sea is evidently. The reasons why are first of all, presence of one of the biggest radioactive sources in Siberia region - Krasnoyarsk mountain-chemical combine which wastes are influenced over the basin of Yenisei and sedimentation of a great amount of suspended particles containing terrigenic organic matter 


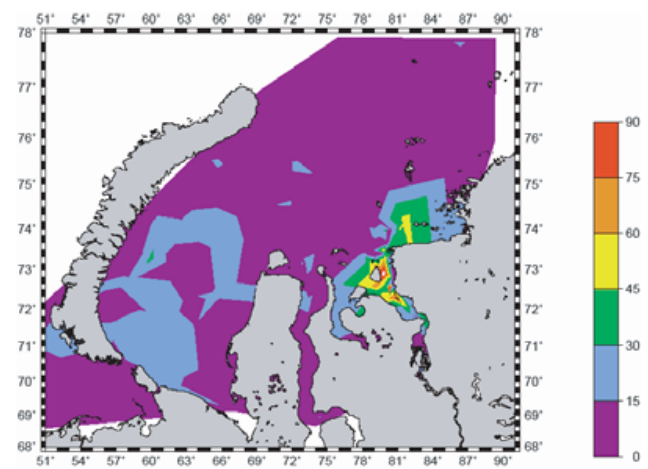

Figure 2. Distribution of Cs-137 (Bq/kg) in surface sediments.

of river runoff in estuarial part. The center of sedimentation is characterized by presence of high waterbearing types of clay silts, which are of high sorption activity to radionuclides, first of all, to caesium and plutonium.

The same influence of a source of radionuclide contamination of Kara Sea is observed also in Ob' river basin. In this case such source is well-known radiochemical plant PO "Mayak". However it's a lot of strong sandy sediments in Ob' estuary zone which are capable to sorb only small part of radiocaesium. And this value is in very good agreemant with amount of clay minerals. The results confirm our previous investigations dedicated to significant dependence of level of ${ }^{137} \mathrm{Cs}$ (and ${ }^{239,240} \mathrm{Pu}$ ) radioactivity on lithological structure of surface sediments.

Features of horizontal distribution of radionuclides in different parts of Kara sea are connected with presence of local sources of radioactive pollution in adjacent areas. Thus, in Kara Gate area in addition of Enisey and $\mathrm{Ob}$ rivers there is strong source of radioactive contamination such as Barents sea area, transferring radioactive dumps from nuclear fuel reprocessing plants Selafield (Great Britain) and La Hague (France) by powerful stream through Kara Gate. Radiocaesium getting to Kara sea, is involved in system of cyclonic stream and partially deposits in suitable places with natural geomorphologic or geochemical (an oxidizing condition in silts) traps.

\section{References}

[1] Mironenko, M.V. and Spasennykh, M.Yu, 1994. The cascade of reservoirs of the Mayak plant. Case history and the version of a computer simulate of Report under DOE coorditation committee on environmental restoration and waste management. Lawrence Berkley Laboratory, RAC-1.

[2] Radioactive Waste Disposal in Seas of Russian Federation: Facts and Problems, 1993. Admin. Prez. Ross.Feder., Moscow (in russian).

[3] Stepanets, O., Borisov, A., Ligaev, A., Solovjeva, G., Sisov, E. and Komarevsky, V., 2003. Radionuclides in the water column and surface sediments of the Yenisei River and adjacent Kara Sea shelf, Siberian river run-off in the Kara Sea. In: Proceedings in Marine Sciences, Elsevier Amsterdam, 6. 